\title{
Membrane-Associated Kaposi Sarcoma-Associated Herpesvirus Glycoprotein B Promotes Cell Adhesion and Inhibits Migration of Cells via Upregulating IL-1 $\beta$ and TNF- $\alpha$
}

\author{
Hosni A.M. Hussein ${ }^{a} \quad$ Usama M. Abdel-Raouf ${ }^{b}$ Shaw M. Akula ${ }^{a}$ \\ a Department of Microbiology and Immunology, Brody School of Medicine at East Carolina University, \\ Greenville, NC, USA; ${ }^{b}$ Faculty of Science, Al Azhar University, Assiut Branch, Assiut , Egypt
}

\author{
Keywords \\ Glycoprotein B · Cytokines - Cell adhesion - Migration · \\ Herpes $\cdot$ IL-1 $\beta \cdot$ TNF- $\alpha \cdot$ Kaposi sarcoma-associated \\ herpesvirus
}

\begin{abstract}
Objectives: Kaposi sarcoma-associated herpesvirus (KSHV) glycoprotein $\mathrm{B}(\mathrm{gB})$ is expressed on the viral envelope as well as on the cytoplasmic membrane of infected cells. In the current study, we aimed to decipher the impact of membraneassociated $\mathrm{gB}$ on adhesion and migration of cells via modulating the expression of cytokines. Methods: A combination of polymerase chain reaction array, cell adhesion assay, and wound-healing migration assay was conducted to study the influence of the gB-induced cytokines on cell adhesion and migration. Results: Membrane-associated gB was demonstrated to significantly upregulate the expression of IL-1 $\beta$ and TNF-a. Elevated levels of these cytokines were observed in conditioned medium (CM) collected from gB-expressing cells (gB-CM) compared to $\mathrm{CM}$ collected from untransfected cells or cells transfected with empty vector. KSHV gB-induced IL-1 $\beta$ and TNF-a play a role in the ability of gB-CM to mediate cell adhesion while inhibiting migration. Conclu-
\end{abstract}

(๑) 2018 S. Karger AG, Basel

E-Mail karger@karger.com www.karger.com/int sion: Our results provide novel evidence that demonstrates full-length gB expressed on cell membrane to mediate adhesion and inhibit migration of cells not only by autocrine mechanism mediated by RGD-based interactions [Hussein et al.: BMC Cancer 2016;16:148], but also by paracrine mechanism mediated by gB-induced IL-1 $\beta$ and TNF-a.

(c) 2018 S. Karger AG, Basel

\section{Introduction}

Kaposi sarcoma-associated virus (KSHV) is an oncogenic virus that is etiologically associated with Kaposi sarcoma (KS), primary effusion lymphoma, and multicentric Castleman disease $[1,2]$. KSHV has a wide range of cell tropism enabling it to infect a variety of cell types while inducing a wide array of cytokines [3]. These cytokines have been shown to be critical for KSHV pathogenicity. Cytokines are a large family of small proteins that are important for a broad range of cell functions including cell attachment, cell migration, and cell-to-cell interactions $[4,5]$. KSHV encodes and induces many cytokines to hijack cellular functions and promote KSHV-associated malignancies $[6,7]$. 
KSHV encodes 7 envelope-associated glycoproteins which facilitate virus binding and entry [8]. KSHV glycoprotein $\mathrm{B}(\mathrm{gB})$ is expressed on the viral envelope as well as on the infected cell membranes. Within the herpesvirus family, KSHV gB is the only glycoprotein that contains the RGD (Arg-Gly-Asp) motif and disintegrin-like domain (DLD) in its N-terminus ectodomain region [9]. Both RGD and DLD are well-characterized integrinbinding domains with an important role in KSHV-cell interactions critical to mediating virus entry into cells [9$11]$. Using soluble $\mathrm{gB}[12]$ and membrane-associated $\mathrm{gB}$ $[13,14]$, it was demonstrated that the RGD motif in KSHV gB can mediate adhesion of cells. Recent work from our laboratory using recombinant $\mathrm{gB}$ proteins lacking both the RGD and DLD domains demonstrated the following: (i) independently, RGD interactions mediate attachment of cells while DLD interactions regulate migration of cells; (ii) however, when both RGD and DLD are placed juxtaposed in the same protein, like in $\mathrm{gB}$, the RGD interaction-induced attachment of cells overshadows the ability of DLD-mediated signaling to induce migration of cells [13]. Such a role for the RGD domain has been proposed in earlier studies $[12,15,16]$. We concluded that the membrane-associated KSHV gB promotes attachment of cells and not migration.

The ability of gB to mediate attachment of cells is by interacting with the extracellular matrix molecules $[12$, 14]. Membrane-associated KSHV gB can also interact with receptors like heparan sulfate [17], integrins [9], and other possible ligands capable of triggering cytokine responses [18-20]. Based on the above facts, we hypothesize that the membrane-bound $\mathrm{gB}$ induces cytokines capable of supporting and promoting the cellular attachment while inhibiting migration. We used a combination of focused arrays and biochemical experimentations to delineate a possible role for the membrane-associated gBinduced paracrine effect of cytokines in promoting attachment of cells compared to migration.

\section{Materials and Methods}

\section{Cells}

The HeLa cell line propagated in DMEM (Invitrogen, Carlsbad, CA, USA) supplemented with $10 \%$ FBS, L-glutamine, and antibiotics was used in this study [13].

\section{Transfection of Cells}

To establish stably transfected HeLa cells expressing recombinant full-length gB protein, cells $\left(5 \times 10^{5}\right.$ cells) were seeded onto 24 -well plates. Following $24 \mathrm{~h}$ of seeding, the cells were transfected with plasmids encoding full-length $\mathrm{gB}$ (gB/pCDNA3.1) using $\mathrm{Fu}$ -
GENE HD transfection reagent (Promega, Madison, WI, USA) as per earlier studies [13]. The transfected cells were cultured in selection medium containing $500 \mu \mathrm{g} / \mathrm{mL}$ of G418 from the second day of transfection for a duration of 8 weeks after which the expression of genes encoding $\mathrm{gB}$ protein were confirmed by flow cytometry and reverse transcriptase-polymerase chain reaction (RT-PCR). At least 2 pools of cells that were under the selection for about 8 weeks were tested in our experiments.

\section{Conditioned Medium}

When the target cells reached $80-90 \%$ confluency, cells were washed with PBS three times, supplemented with DMEM supplemented with $2 \% \mathrm{FBS}$ and further incubated at $37^{\circ} \mathrm{C}$. After 48 -h incubation, the supernatant was collected and labeled as the conditioned medium (CM). Collected $\mathrm{CM}$ was centrifuged at 1,000 rpm for $10 \mathrm{~min}$ at $4{ }^{\circ} \mathrm{C}$ and stored at $-80^{\circ} \mathrm{C}$ for further experiments. CM collected from untransfected, mock transfected, transfected with $\mathrm{gB} / \mathrm{pCDNA3}$.1, or pCDNA3.1 are referred to as untransfected CM, mock-CM, gB-CM, or pCDNA3.1-CM, respectively.

\section{PCR Arrays}

We analyzed how cell membrane-associated gB induced cytokine expression in HeLa cells using human common cytokine PCR arrays. Briefly, stably transfected HeLa cells were lysed, RNA was extracted, and cDNA was prepared. The cDNA was later used to analyze the profile of cytokine expression using the PCR array (catalog No. PHAS-021) as per the manufacturer's recommendations (SABiosciences, Frederick, MD, USA).

\section{Polymerase Chain Reaction}

PCRs were conducted using synthesized cDNA and specific primers for TNF- $\alpha$ [21] and IL-1 $\beta$ [22]. PCR amplifications were performed using Platinum Taq DNA Polymerase, High Fidelity (Life Technologies) as per earlier studies [23].

\section{Enzyme-Linked Immunosorbent Assay}

Enzyme-linked immunosorbent assay (ELISA) was used to confirm expression of cytokines in CM. Briefly, high-binding 96well plates were coated with specific primary antibody, nonspecific controls, bovine serum albumin (BSA) or glutathione S-transferase in $100 \mathrm{~mm}$ bicarbonate/carbonate coating buffer overnight at $4{ }^{\circ} \mathrm{C}$. Plates were washed 5 times with wash buffer (PBS containing $0.1 \%$ Tween 20 ), blocked for 30 min with $1 \%$ BSA blocking solution containing $0.1 \%$ Tween 20 , washed 5 times with wash buffer, and further incubated at room temperature (RT) for $30 \mathrm{~min}$ with appropriate test samples. These plates were once again sequentially incubated at RT for $1 \mathrm{~h}$ with specific primary antibodies, followed by a 1-h incubation at RT with goat anti-rabbit conjugated to horseradish peroxidase (or goat anti-mouse horseradish peroxidase). After reaction with $3,3^{\prime}, 5,5^{\prime}$-tetramethylbenzidine substrate, the reaction was stopped by $1 \mathrm{~N} \mathrm{HCl}$ and read at $450 \mathrm{~nm}$.

\section{Cell Adhesion Assay}

Cell adhesion assays were performed as per earlier methods [24]. Maxisorp 96-well immune plates (Thermo Fisher Scientific, Waltham, MA, USA) were coated with $1 \%$ collagen for $60 \mathrm{~min}$ at RT and blocked with $1 \%$ BSA in PBS for 30 min at RT. HeLa cells were trypsinized and seeded at a concentration of $2 \times 10^{4}$ cells/well in $100 \mu \mathrm{L}$ of gB-CM or gB-CM supplemented with antibodies $(20$ 


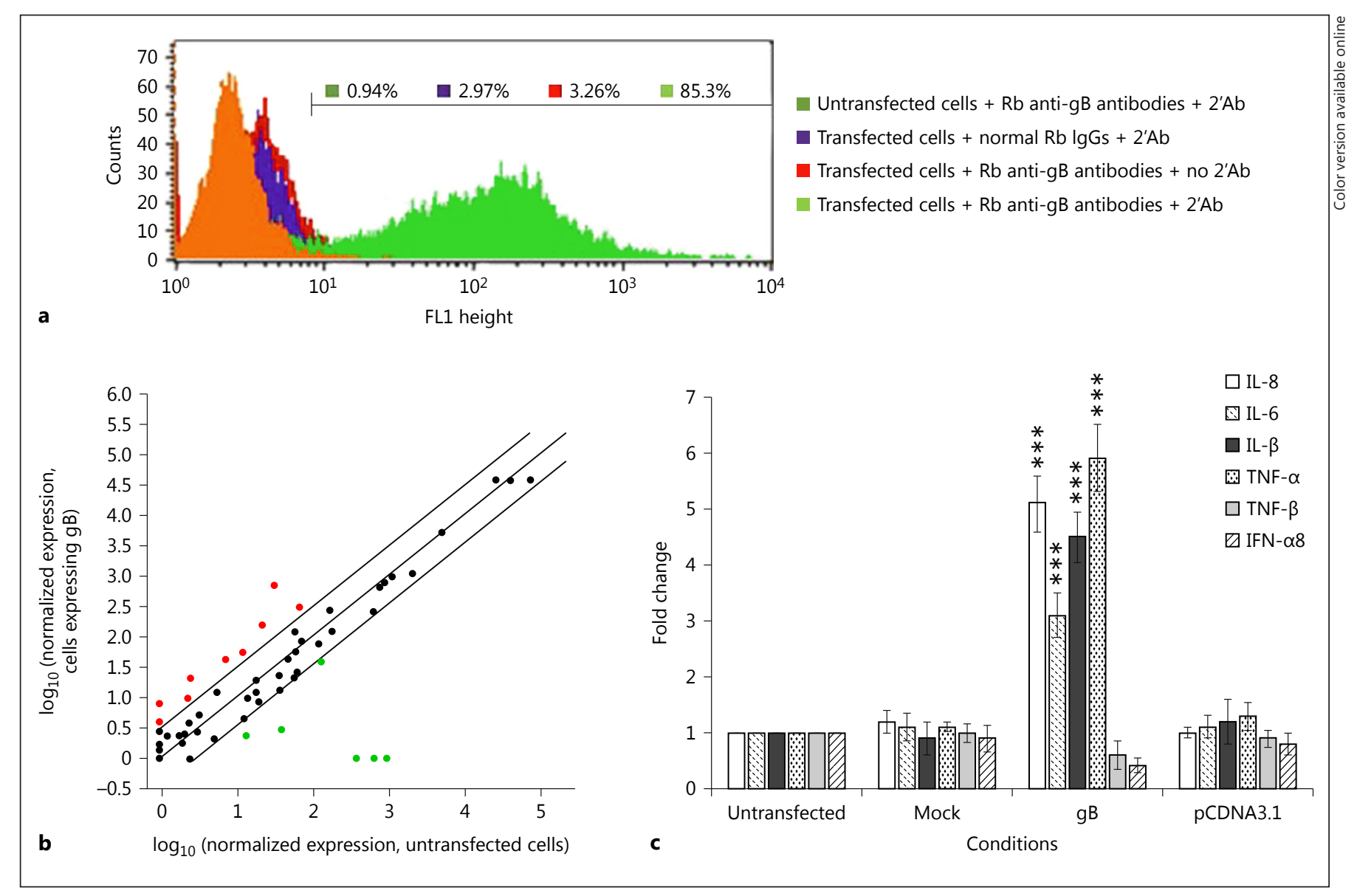

Fig. 1. Cell membrane-bound gB induces expression of IL-1 $\beta$ and TNF- $\alpha$. a Flow cytometry data confirming the expression of $g B$ protein in transfected cells. HeLa cells stably transfected with gB/ pCDNA3.1 vector were analyzed for the expression of gB protein. This was performed by staining untransfected cells and transfected cells with rabbit polyclonal anti-gB antibodies followed by incubation with goat anti-rabbit FITC, before examining by FACS. Appropriate controls in the form of different antibodies were used. The average number of cells positive for the surface expression of gB from three independent experiments is provided over the marker. b Scatter plot showing expression of cytokine genes in HeLa cells stably transfected with $\mathrm{gB} / \mathrm{pCDNA} 3.1$ compared to untransfected cells. Expression of cytokine genes were quantified using human cytokine PCR arrays. Data were normalized, and the relative expression levels for each gene in $\mathrm{gB} / \mathrm{pCDNA3.1-trans-}$

$\mathrm{ng} / \mathrm{mL}$ ) to IL-1 $\beta$ (rabbit anti-IL-1 $\beta$ antibodies, Cell Signaling Technology, Danvers, MA, USA), TNF- $\alpha$ (rabbit anti-TNF- $\alpha$ antibodies, Cell Signaling Technology), IL- $1 \beta$ and TNF- $\alpha$, pre-immune IgG, or DMEM supplemented with $2 \%$ FBS containing different concentrations of recombinant IL- $1 \beta$ or TNF- $\alpha$ (Thermo Fisher Scientific). The plate contents were incubated at $37^{\circ} \mathrm{C}$ in a $5 \% \mathrm{CO}_{2}$ atmosphere with $100 \%$ humidity for $1 \mathrm{~h}$ and washed 4 times with serum-free DMEM, and the adherent cells were fixed with $4 \%$ paraformaldehyde in PBS for 30 min at RT. Adherent cells

KSHV gB Promotes Cell Adhesion via Upregulating IL- $1 \beta$ and TNF- $\alpha$ fected cells and untransfected cell are plotted against each other; black dots indicate no change in gene expression from untransfected cell, red and green dots indicate upregulation and downregulation, respectively. c Expression of IL-8, IL-6, IL-1 $\beta$, TNF- $\alpha$, TGF- $\beta$, and IFN- $\alpha 8$ detected by PCR arrays were confirmed using qRT-PCR. Data plotted for the expression of IL-1 $\beta$; these cytokines in $\mathrm{gB} / \mathrm{pCDNA3.1-transfected} \mathrm{cells}(\mathrm{gB})$ and mock-transfected cells (mock) were compared to untransfected cells. The relative expression was measured in terms of cycle threshold value and normalized to actin expression. The $x$ axis indicates transfection and $y$ axis indicates fold change in the expression of cytokines. The Student $t$ test was performed to compare expression of IL- $1 \beta$ and TNF- $\alpha$ under different conditions. Two-tailed $p$ value of 0.05 or less was considered statistically significant; ${ }^{* * *} p<0.001$.

were washed and stained with $0.5 \%$ crystal violet in water with $20 \%$ ( $\mathrm{vol} / \mathrm{vol}$ ) methanol for $15 \mathrm{~min}$ at RT. After $15 \mathrm{~min}$, the cells were extensively washed in PBS, dye was extracted with $0.1 \mathrm{M}$ sodium citrate and quantified by the measurement of absorbance at 595 $\mathrm{nm}$ in an ELISA plate reader.

\section{Wound-Healing Migration Assay}

HeLa cells were grown to $80-90 \%$ confluence in $1 \%$ collagencoated 24-well plates. The monolayers of cells were wounded by 
Table 1. Expression of genes significantly altered by KSHV-gB

\begin{tabular}{|c|c|c|c|}
\hline Gene name & $\begin{array}{l}\text { GenBank accession } \\
\text { No. }\end{array}$ & Gene symbol & $\begin{array}{l}\text { Fold change in gene } \\
\text { expression }\end{array}$ \\
\hline \multicolumn{4}{|l|}{ Upregulated } \\
\hline Colony stimulating factor 1 & BC021117 & CSF1 & 4.5 \\
\hline Growth differentiation factor 9 & ВC096230 & GDF9 & 2.16 \\
\hline Inhibin- $\beta$ A subunit & BC007858 & INHBA & 5.66 \\
\hline Interferon- $\alpha 2$ & BC104164 & IFNA2 & 3.97 \\
\hline Interleukin-1 $\alpha$ & BC013142 & IL1A & 4.5 \\
\hline Interleukin $1 \beta$ & ВC008678 & IL1B & 4.35 \\
\hline Interleukin-6 & BC015511 & IL6 & 2.04 \\
\hline Interleukin-8 & BC013615 & IL8 & 5 \\
\hline Interleukin-10 & BC104252 & IL10 & 2.81 \\
\hline Interleukin-11 & BC012506 & IL11 & 4.8 \\
\hline Interleukin-20 & ВC074949 & IL20 & 4.14 \\
\hline Transforming growth factor- $\beta 1$ & BC000125 & TGFb1 & 2.0 \\
\hline Transforming growth factor- $\beta 2$ & BC096235 & TGFb2 & 2.5 \\
\hline Tumor necrosis factor & BC028148 & TNF & 5.9 \\
\hline TNF superfamily member 14 & BC152848 & TNFSF14 & 3.9 \\
\hline \multicolumn{4}{|l|}{ Downregulated } \\
\hline Bone morphogenetic protein-2 & BC035097 & BMP2 & 0.34 \\
\hline Bone morphogenetic protein- 5 & BC027958 & BMP5 & 0.4 \\
\hline Bone morphogenetic protein- 8 & BC023526 & BMP8 & 0.28 \\
\hline CD70 molecule & BC000725 & CD70 & 0.28 \\
\hline Inhibin- $\alpha$ subunit & BC006391 & INHA & 0.4 \\
\hline Interleukin-7 & BC047698 & IL7 & 0.38 \\
\hline Interferon- $\kappa$ & BC140280 & IFNK & 0.41 \\
\hline Interferon- $\alpha 8$ & BC104828 & IFNA8 & 0.41 \\
\hline Platelet-derived growth factor subunit A & $\mathrm{AC} 147651$ & PDGFA & 0.35 \\
\hline
\end{tabular}

performing a scratch with a sterile $1,000-\mu \mathrm{L}$ micropipette tip as described earlier [13]. Cells were washed with DMEM, and further incubated at $37^{\circ} \mathrm{C}$ in untransfected CM, mock-CM, pCDNA3.1$\mathrm{CM}$, gB-CM, or gB-CM containing specific antibodies to IL- $1 \beta$, TNF- $\alpha$, a combination of IL- $1 \beta$ and TNF- $\alpha$, or DMEM supplemented with $2 \%$ FBS containing different concentrations of recombinant IL- $1 \beta$ or TNF- $\alpha$. Wound closure was monitored at 0 and $16 \mathrm{~h}$ following scratch and imaged with a laser scanning LSM 510 Carl Zeiss confocal microscope (magnification, $\times 20$ objective). The open area (scratch) was quantified with TScratch software.

Transwell Migration Assay

A three-dimensional cell migration assay was performed using a Transwell $8-\mathrm{mm}$ permeable membrane insert coated with a $1 \%$ collagen solution (Millipore Corp., Billerica, MA, USA). HeLa cells were cultured for $24 \mathrm{~h}$ in serum-free medium. $100 \mu \mathrm{L}$ of $1 \times 10^{6}$ cells/mL suspension was added to the upper chamber of 24-well Transwell plates. Untransfected CM, mock-CM, pCDNA3.1-CM, gB-CM, or gB-CM containing specific antibodies to IL- $1 \beta$, TNF- $\alpha$, a mixture of IL- $1 \beta$ and TNF- $\alpha$, or DMEM supplemented with $2 \%$ FBS containing different concentrations of recombinant IL- $1 \beta$ or TNF- $\alpha$ was added to the bottom chamber and incubated at $37^{\circ} \mathrm{C}$. At the end of the 16-h incubation, the nonmigrated cells on the upper face of the membrane were removed by using a sterile cotton swab and migrated cells on the lower face were fixed in parafor- maldehyde, permeabilized by methanol (100\%) for $10 \mathrm{~min}$, stained with crystal violet for $30 \mathrm{~min}$ and quantitated by microscopy [25].

\section{Results}

\section{Cell Membrane-Bound $g B$ Induces $I L-1 \beta$ and TNF- $\alpha$}

To study the effect of membrane-bound gB in altering the expression of cytokines, we used HeLa cells expressing gB. The recombinant form of the full-length gB was expressed on the cell membrane as monitored by flow cytometer (Fig. 1a). In this case, the cells were live and processed at $+4^{\circ} \mathrm{C}$ rather than fixing them to specifically measure the surface expression of the fully processed gB. We used the above cells to analyze the expression profile of cytokines using PCR arrays. We used two different cells in the experiment: HeLa cells expressing gB or untransfected cells. The cells were about $85-90 \%$ confluent when they were lysed, RNA isolated, cDNA synthesized, and PCR performed. The differences in the profile of 66 cytokines in cells expressing recombinant gB were detected (Fig. $1 \mathrm{~b}$ 


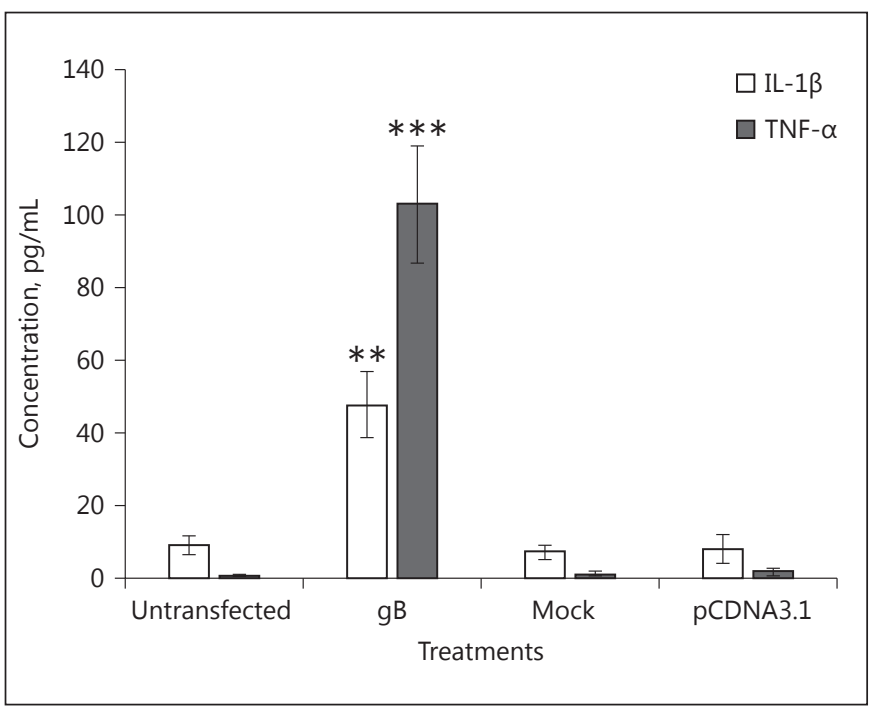

Fig. 2. Quantification of IL-1 $\beta$ and TNF- $\alpha$ levels in conditioned medium (CM) by ELISA. The level of IL- $1 \beta$ and TNF- $\alpha$ in the CM obtained from HeLa cells under different transfection conditions was quantified by ELISA. Data plotted is for cytokine levels in gBCM, pCDNA3.1-CM, and mock-CM compared to untransfected$\mathrm{CM}$. The Student $t$ test was performed to compare groups. Twotailed $p$ value of 0.05 or less was considered statistically significant; ** $p<0.01 ; * * * p<0.001$.

and online suppl. Fig. 1; for all online suppl. material, see www.karger.com/doi/10.1159/000487596). We identified 13 specific genes (out of a total of 66 genes) that were altered significantly ( $\geq 2.0$-fold) in cells expressing gB compared to the untransfected cells (Table 1). Of these, we were interested in the expression profile of two genes, IL$1 \beta$ and TNF- $\alpha$, that were elevated in cells expressing $\mathrm{gB}$ compared to untransfected cells. We focused on IL-1 $\beta$ and TNF- $\alpha$ because of the following three reasons: (i) the expression of these two cytokines is induced by membraneassociated gB (Fig. 1b); (ii) the expression of these cytokines is elevated in KS tumors [26, 27]; and (iii) both these cytokines are known to promote adhesion and inhibit migration of cells $[24,28,29]$. We authenticated the array results by performing qRT-PCR using RNA extracted from untransfected, mock-transfected, cells transfected with $\mathrm{gB} / \mathrm{pCDNA3.1}$, or pCDNA3.1 (Fig. 1c). The results implicate the ability of membrane-associated $\mathrm{gB}$ to induce a variety of growth factors including IL- $1 \beta$ and TNF- $\alpha$.

Additionally, we tested the ability of gB-induced IL- $1 \beta$ and TNF- $\alpha$ at the translational level by monitoring their expression in the cell supernatant. ELISA was conducted to monitor the gB-induced cytokines in the HeLa cell supernatant (Fig. 2). The supernatants collected from $\mathrm{HeLa}$ cells expressing gB had elevated levels of both IL- $1 \beta$ and TNF- $\alpha$ compared to untransfected, mock-transfected, or cells transfected with the empty vector (pCDNA3.1). These results are a proof that gB can potentially induce IL- $1 \beta$ and TNF- $\alpha$.

gB-Induced IL- $1 \beta$ and TNF- $\alpha$ Mediate Adhesion of Cells

Our earlier studies utilized cell adhesion assays effectively by employing soluble $\mathrm{gB}(\mathrm{gB} \Delta \mathrm{TM})$ to decipher the role of $g B$ in mediating attachment of cells $[12,13]$. In the current study, we used a similar approach to analyze the effect of gB-induced cytokines in mediating attachment of cells (Fig. 3). gB-CM significantly promoted attachment of cells compared to unconditioned medium, untransfected CM, or mock-CM (Fig. 3a). Incubating cells with $\mathrm{gB}-\mathrm{CM}$, or $\mathrm{gB}-\mathrm{CM}$ containing specific antibodies to TNF- $\alpha$ or IL- $1 \beta$, significantly hampered the ability of cells to bind wells coated with $1 \%$ collagen compared to incubating with preimmune IgG (Fig. 3b). We also observed an additive inhibitory effect on the ability of cells to bind wells when incubated with a combination of antibodies to IL- $1 \beta$ and TNF- $\alpha$. Likewise, we found a significant increase in adhesion of cells treated with the recombinant form of IL-1 $\beta$ (Fig. 3c) or TNF- $\alpha$ (Fig. 3d).

\section{gB-Induced IL- $1 \beta$ and TNF- $\alpha$ Inhibit Cell Migration}

To understand the role of gB-induced IL- $1 \beta$ and TNF- $\alpha$ in promoting attachment versus migration, we performed cell migration assay. We observed a significant inhibition in the migration of cells treated with gB-CM compared to untreated cells (Fig. 4). There was a significant migration of HeLa cells treated with gB-CM supplemented with antibodies to IL- $1 \beta$ and TNF- $\alpha$ compared to those cells that were either untreated or treated with gBCM (Fig. 4a). Quantification of the wound closure is represented by the bar diagram in Figure $4 \mathrm{~b}$. These results were based on monitoring cell migration at $16 \mathrm{~h}$ following scratch. The results from wound healing assays were further confirmed by performing a three-dimensional cell migration assay with the Transwell system (Fig. 4c). We observed significant inhibition in the migration of cells treated with gB-CM compared to untreated cells (Fig. 4c). There was a significant migration of HeLa cells when CM was used in the presence of antibodies to IL- $1 \beta$, TNF- $\alpha$, or in combination when compared to preimmune IgG (Fig. 4c). Exogenous supplementation of cells with recombinant IL-1 $\beta$ (Fig. 4d) or TNF- $\alpha$ (Fig. 4e) significantly inhibited migration of cells. These results provide an insight into the role of gB-induced IL- $1 \beta$ and TNF- $\alpha$ in mediating HeLa cell attachment versus cell migration. 

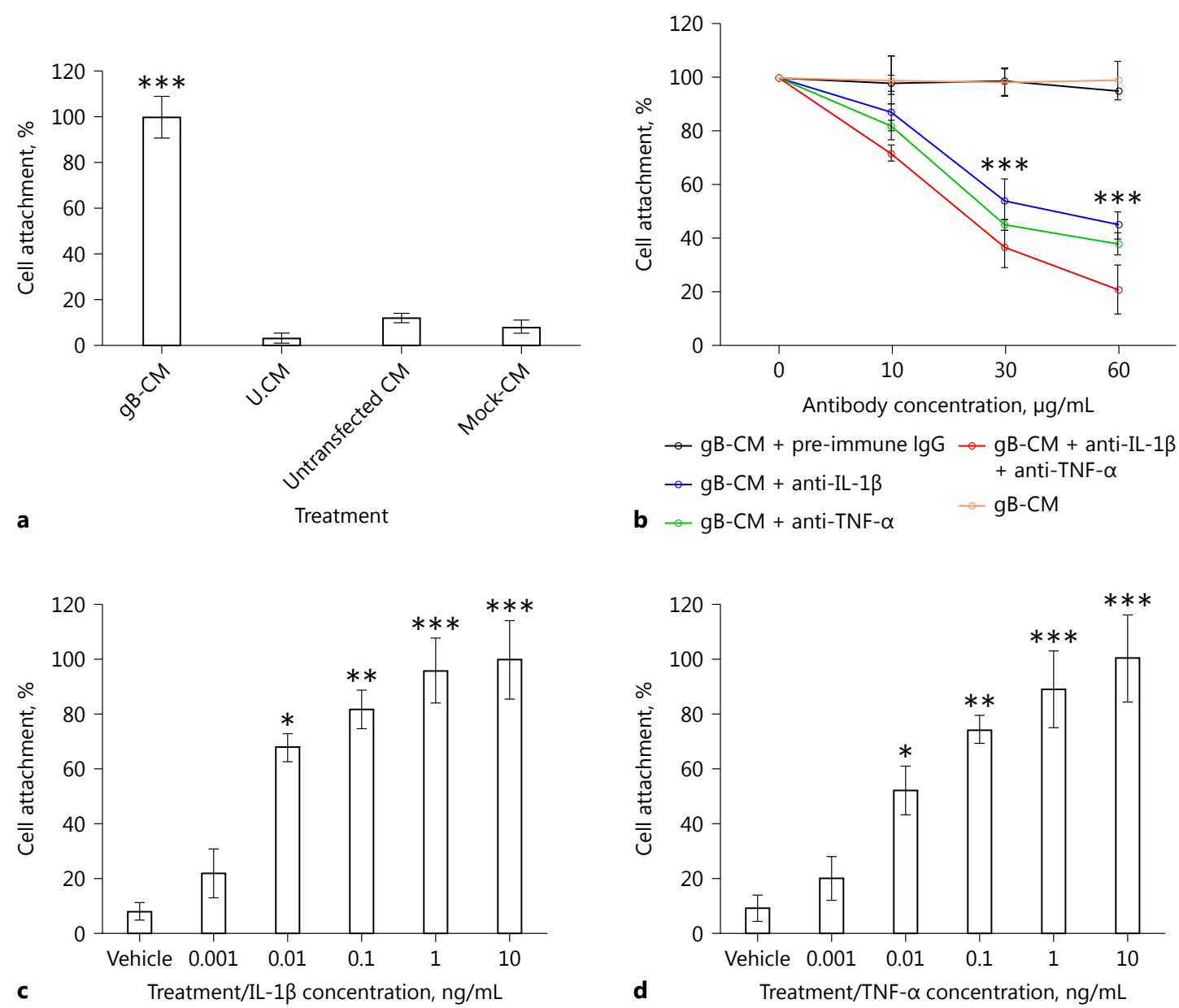

Fig. 3. IL-1 $\beta$ and TNF- $\alpha$ in the gB-CM is crucial to mediating cell adhesion. Maxisorp 96-well immune plates were coated with $1 \%$ collagen for 60 min at RT, blocked with $1 \%$ bovine serum albumin (BSA) in PBS for 30 min at RT, washed, and cell adhesion assays performed. a Data were plotted for adhesion of HeLa cells incubated with gB-CM, unconditioned medium (U.CM), untransfected CM, or mock-CM. Data are presented as percentage cell adhesion observed in cells incubated with U.CM. b Data were plotted for adhesion of HeLa cells incubated with gB-CM only, gB-CM supplemented with preimmune IgG, anti-IL-1 $\beta$, anti-TNF- $\alpha$, or a combination of anti-IL- $1 \beta$ and anti-TNF- $\alpha$. Data are presented as percentage cell adhesion observed in cells incubated with $\mathrm{gB}-\mathrm{CM}$

\section{Discussion}

KSHV infection is characterized by abundant expression of cytokines [26]. These cytokines are deemed to be critical for KSHV infection and disease progression, particularly in AIDS-associated KS [30-33]. It has been reported that the initial attachment of virus to cell surface

only. c, d Maxisorp 96-well immune plates were coated with $1 \%$ collagen for 60 min at RT, blocked with 1\% BSA in PBS for 30 min at RT, washed, and cell adhesion assays performed. Data were plotted for adhesion of HeLa cells incubated with DMEM supplemented with $2 \%$ FBS containing different concentration of recombinant IL-1 $\beta$ (c), or recombinant TNF- $\alpha(\mathbf{d})$. Data are presented as percentage cell adhesion observed in each treatment compared to the cells incubated with DMEM supplemented with 2\% FBS containing vehicle. The Student $t$ test was performed to compare the groups (a-d). Two-tailed $p$ value of 0.05 or less was considered statistically significant; ${ }^{*} p<0.05 ;{ }^{* *} p<0.01$; ${ }^{* *} p<0.001$.

molecules is one of the key steps required for activation of cellular signaling-induced expression of cytokines [3436]. Envelope glycoprotein $\mathrm{gB}$ interacts with a variety of cell surface molecules including heparan sulfate and integrins to facilitate virus binding and entry $[9,17]$. There is growing evidence that demonstrates significant roles of $\mathrm{gB}$ interactions to modulate a variety of cell signaling 

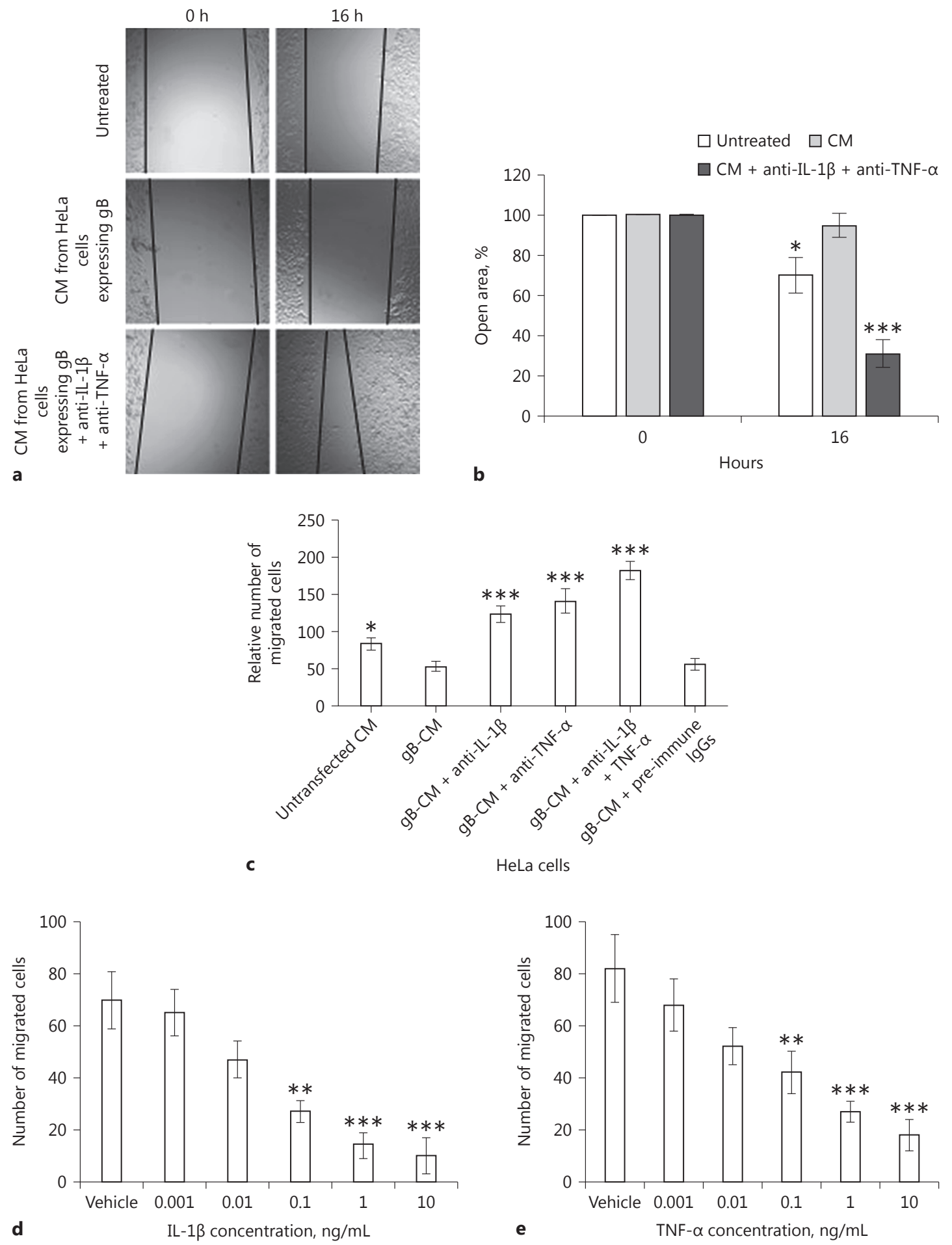
pathways to induce a cellular state that is receptive for virus replication $[13,14,23,37]$. In a recent study, we demonstrated cell membrane-associated $\mathrm{gB}$ to promote adhesion over migration of infected cells via RGD motif [13]. Promoting cell adhesion by gB during lytic replication of KSHV supports the active replication of virus and could assist KSHV in avoiding host immune responses [14]. The mechanism by which gB promotes adhesion over migration of cells is not fully understood. We hypothesized that the ability of gB to induce cytokines could support and promote RGD-based attachment of cells while inhibiting cell migration.

In the present study, we employed HeLa cells stably expressing full length of KSHV gB (Fig. 1a) to study the cytokine profile using PCR arrays. Our results demonstrated $\mathrm{gB}$ to significantly alter the expression profile of many cytokines (Fig. 1b, online suppl. Fig. 1). These observations demonstrate that $\mathrm{KSHV}$ active replication is not required for induction of cellular cytokines and $\mathrm{gB}$ interactions with surface molecule is able to induce these cytokines [34, 36]. Many of cellular cytokines have been shown to be significantly upregulated in gB-expressing cells by more than 2 -fold changes (Table 1 ) including IL$1 \beta$ and TNF- $\alpha$. Interestingly, IL- $1 \beta$ and TNF- $\alpha$ have been shown to enhance cell adhesion and inhibit cell migration $[24,28,29,38]$. Hence, we focused our experiments to analyze the role of gB-induced IL- $1 \beta$ and TNF- $\alpha$ on cell adhesion and migration. qRT-PCR data confirmed the increase in expression levels of IL- $1 \beta$ and TNF- $\alpha$ in gBexpressing HeLa cells compared to untransfected cells (Fig. 1c). Likewise, we found a significant increase in the level of IL-1 $\beta$ and TNF- $\alpha$ in CM collected from cells transfected with $\mathrm{gB}$ comparing to untransfected cells or cells transfected with empty vector or mock (Fig. 2). Although the levels of IL- $1 \beta$ and TNF- $\alpha$ were significantly

Fig. 4. Antibodies to IL-1 $\beta$ and TNF- $\alpha$ accelerate cell migration by gB-CM. a $80-90 \%$ confluent HeLa cells in 24-well plates were washed with DMEM, scratched with a $1,000-\mu \mathrm{L}$ pipette tip, and further incubated at $37^{\circ} \mathrm{C}$ in untransfected CM, pCDNA3.1-CM, mock-CM, gB-CM, or gB-CM containing specific antibodies to TNF- $\alpha$, IL- $1 \beta$, or a combination of TNF- $\alpha$ and IL- $1 \beta$. Wound closure was monitored at 0 and $16 \mathrm{~h}$ following scratch and imaged with a laser scanning LSM 510 Carl Zeiss confocal microscope (magnification, $\times 20$ objective). A representative image of cell migration is provided. $\mathbf{b}$ All the wound-healing assays performed in this study were independently repeated five times. The open area (scratch) was quantified with TSratch software and the data represented as a histogram. c Data from Transwell migration assays demonstrating the migration pattern of HeLa cells through a per- elevated in cells expressing gB (Fig. 1c), we found TNF- $\alpha$ protein levels to be markedly elevated compared to IL- $1 \beta$ protein in gB-CM (Fig. 2). This difference could be attributed to one or both of the following reasons: (i) the inherent differences between the techniques used to monitor expression of the transcripts (qRT-PCR) versus protein levels (ELISA); (ii) specificity/sensitivity of the antibodies that were used in ELISA. Despite this difference, our results clearly indicate that the cell membrane-associated $\mathrm{gB}$, independent of the virus replication, can induce expression and release of IL- $1 \beta$ and TNF- $\alpha$.

Our results demonstrate that the CM from gB-expressing cells significantly promotes cell adhesion (Fig. 3a). However, CM supplemented with antibodies specific to IL- $1 \beta$ and TNF- $\alpha$ or to both cytokines compared to preimmune IgG remarkably decreased adhesion of cells (Fig. 3b). Also, there was a significant increase in the adhesion of cells treated with recombinant IL- $1 \beta$ (Fig. 3c) or TNF- $\alpha$ (Fig. 3d). These results confirmed the ability of IL- $1 \beta$ and TNF- $\alpha$ to enhance cell adhesion [24, 28 ] and demonstrated these cytokines to be indispensable for gB-CM-induced attachment of cells. Moreover, our results provide a glimpse into how full-length $\mathrm{gB}$ promote cell adhesion by not only autocrine mechanism $[12,14]$ but also by paracrine effect via modulating the expression of IL- $1 \beta$ and TNF- $\alpha$.

Finally, to understand the effect of these cytokines on cell migration, we employed CM from gB-expressing cells in wound-healing migration assay. We observed maximum migration in cells incubated with $\mathrm{gB}-\mathrm{CM}$ supplemented with antibodies specific to IL- $1 \beta$ and TNF- $\alpha$ compared to untreated cells, while least migration of cells was observed in cells treated with gB-CM alone (Fig. 4a, b). We got similar results while using a three-dimensional cell migration assay with the Transwell system (Fig. 4c).

meable membrane when cells were incubated with gB-CM containing specific antibodies to IL- $1 \beta$, TNF- $\alpha$, or a combination of IL- $1 \beta$ and TNF- $\alpha$ compared to cells incubated with gB-CM or untransfected CM. The Student $t$ test was performed to compare groups. d, e Data from Transwell migration assays demonstrating the migration pattern of HeLa cells through a permeable membrane when cells were incubated with DMEM supplemented with $2 \%$ FBS containing different concentrations of recombinant IL- $1 \beta$ (d), or recombinant TNF- $\alpha$ (e) compared to cells incubated with DMEM supplemented with $2 \%$ FBS containing vehicle. The Student $t$ test was performed to compare the groups (b-e). Two-tailed $p$ value of 0.05 or less was considered statistically significant; ${ }^{*} p<$ 0.05 ;* $^{* *}<0.01$; $^{* * *} p<0.001$. 
These observations are consistent with earlier studies [13, 29]. In fact, recombinant IL- $1 \beta$ (Fig. $4 \mathrm{~d}$ ) and TNF- $\alpha$ (Fig. 4e) limited migration of cells as well. In all, cell membrane-associated gB-induced IL- $1 \beta$ and TNF- $\alpha$ promote attachment of cells compared to migration.

In summary, $\mathrm{gB}$ is not only expressed on the viral envelope but also on the cytoplasmic membrane of infected cells during lytic stages of replication [17]. In vivo, only $2-5 \%$ of infected cells support a lytic phase of replication [39]. The lytic phase of replication occurs in cells that are predominantly in the S-phase of cell division [40]. Interestingly, $\mathrm{gB}$ is said to mediate attachment of cells via its RGD motif [13]; specifically in cells from the S-phase of cell division [14]. The present study delineates the paracrine effects of $\mathrm{gB}$ on cell adhesion and migration. The study demonstrates the ability of $g B$-induced TNF- $\alpha$ and IL- $1 \beta$ to promote adhesion of cells and inhibit cell migration. Interestingly, both these cytokines are elevated in KS tumors [26]. These observations are consistent with previous work that full-length $\mathrm{gB}$ promote cell adhesion [13]. Since adhesion of infected cells is crucial to the pathobiology of KSHV-induced tumors, it is mediated by more than one mechanism: (i) by autocrine mechanism mediated by RGD-based interactions [13] and (ii) by paracrine mechanism mediated by IL- $1 \beta$ and TNF- $\alpha$ (the current study). Taken together, we conclude that the cell membrane-associated KSGV gB-induced IL- $1 \beta$ and TNF- $\alpha$ could work in a synergistic fashion with RGD motif-driven signaling to maximize the function of $\mathrm{gB}$ in directly promoting adhesion of latently infected cells. This in- crease in adhesion prevents cells from migration. Even more, attachment of KSHV-infected cells is crucial to the biology of KSHV that it needs to have redundant mechanisms (autocrine and paracrine) regulating it. Our future work will be dedicated to delineating the mechanism by which $\mathrm{gB}$-induced IL- $1 \beta$ and TNF- $\alpha$ mediate cell adhesion and inhibit cell migration.

\section{Acknowledgements}

We thank Dr. Adrian Reber, Centers for Disease Control and Prevention, to have read and critiqued this report. The study was funded in part by the Merck Investigator-Initiated Studies Program.

\section{Statement of Ethics}

This study does not involve human subjects or animals.

\section{Disclosure Statement}

The authors declare no competing financial interests.

\section{Author Contributions}

H.A.M.H. and S.M.A. designed the project and wrote the manuscript. H.A.M.H. performed the experiments; S.M.A. cloned the vector expressing $\mathrm{gB}$. All authors analyzed the data, provided intellectual input, and edited the manuscript.

\section{References}

1 Hussein HAM, Akula SM: Profiling of cellular microRNA responses during the early stages of KSHV infection. Arch Virol 2017;162: 3293-3303.

2 Chandran B: Early events in Kaposi's sarcoma-associated herpesvirus infection of target cells. J Virol 2010;84:2188-2199.

3 Giffin L, Damania B: KSHV: pathways to tumorigenesis and persistent infection. Adv Virus Res 2014;88:111-159.

4 Clahsen T, Schaper F: Interleukin-6 acts in the fashion of a classical chemokine on monocytic cells by inducing integrin activation, cell adhesion, actin polymerization, chemotaxis, and transmigration. J Leukoc Biol 2008;84: 1521-1529.

5 Wang SL, Shi XH, Yang Z, Zhang YM, Shen LR, Lei ZY, Zhang ZQ, Cao C, Fan DL: Osteopontin $(\mathrm{OPN})$ is an important protein to mediate improvements in the biocompatibility of C ion-implanted silicone rubber. PLoS One 2014;9:e98320.
6 West J, Damania B: Upregulation of the TLR3 pathway by Kaposi's sarcoma-associated herpesvirus during primary infection. J Virol 2008;82:5440-5449.

7 Bussey KA, Reimer E, Todt H, Denker B, Gallo A, Konrad A, Ottinger M, Adler H, Sturzl M, Brune W, Brinkmann MM: The gammaherpesviruses Kaposi's sarcoma-associated herpesvirus and murine gammaherpesvirus 68 modulate the Toll-like receptor-induced proinflammatory cytokine response. J Virol 2014;88:9245-9259.

-8 Bandyopadhyay C, Valiya-Veettil M, Dutta D, Chakraborty S, Chandran B: CIB1 synergizes with EphrinA2 to regulate Kaposi's sarcoma-associated herpesvirus macropinocytic entry in human microvascular dermal endothelial cells. PLoS Pathog 2014;10:e1003941.
Akula SM, Pramod NP, Wang FZ, Chandran B: Integrin alpha3betal (CD 49c/29) is a cellular receptor for Kaposi's sarcoma-associated herpesvirus (KSHV/HHV-8) entry into the target cells. Cell 2002;108:407-419.

10 Veettil MV, Sadagopan S, Sharma-Walia N, Wang FZ, Raghu H, Varga L, Chandran B: Kaposi's sarcoma-associated herpesvirus forms a multimolecular complex of integrins (alphaVbeta5, alphaVbeta3, and alpha3beta1) and CD98-xCT during infection of human dermal microvascular endothelial cells, and CD98-xCT is essential for the postentry stage of infection. J Virol 2008;82:12126-12144.

$\checkmark 11$ Garrigues HJ, Rubinchikova YE, Dipersio CM, Rose TM: Integrin alphaVbeta 3 binds to the RGD motif of glycoprotein B of Kaposi's sarcoma-associated herpesvirus and functions as an RGD-dependent entry receptor. J Virol 2008;82:1570-1580.
KSHV gB Promotes Cell Adhesion via Upregulating IL- $1 \beta$ and TNF- $\alpha$ 
$\checkmark 12$ Wang FZ, Akula SM, Sharma-Walia N, Zeng L, Chandran B: Human herpesvirus 8 envelope glycoprotein $B$ mediates cell adhesion via its RGD sequence. J Virol 2003;77:3131-3147.

$\checkmark 13$ Hussein HA, Walker LR, Akula SM: KSHV gB associated RGD interactions promote attachment of cells by inhibiting the potential migratory signals induced by the disintegrin-like domain. BMC Cancer 2016;16:148.

14 Dyson OF, Oxendine TL, Hamden KE, Ford PW, Akula SM: Differential regulation of the attachment of Kaposi's sarcoma-associated herpesvirus (KSHV)-infected human B cells to extracellular matrix by KSHV-encoded gB and cellular alphaV integrins. Cell Microbiol 2008;10:1546-1558.

-15 Lu D, Xie S, Sukkar MB, Lu X, Scully MF, Chung KF: Inhibition of airway smooth muscle adhesion and migration by the disintegrin domain of ADAM-15. Am J Respir Cell Mol Biol 2007;37:494-500.

-16 Sun C, Wu MH, Guo M, Day ML, Lee ES, Yuan SY: ADAM15 regulates endothelial permeability and neutrophil migration via $\mathrm{Src} /$ ERK1/2 signalling. Cardiovasc Res 2010;87: 348-355.

-17 Akula SM, Pramod NP, Wang FZ, Chandran B: Human herpesvirus 8 envelope-associated glycoprotein B interacts with heparan sulfatelike moieties. Virology 2001;284:235-249.

-18 Cooper A, Tal G, Lider O, Shaul Y: Cytokine induction by the hepatitis $B$ virus capsid in macrophages is facilitated by membrane heparan sulfate and involves TLR2. J Immunol 2005; 175:3165-3176.

19 DiPersio CM, Zheng R, Kenney J, Van De Water L: Integrin-mediated regulation of epidermal wound functions. Cell Tissue Res 2016;365:467-482.

20 Jacques A, Bleau C, Turbide C, Beauchemin N, Lamontagne L: Macrophage interleukin-6 and tumour necrosis factor-alpha are induced by coronavirus fixation to Toll-like receptor 2/heparan sulphate receptors but not carcinoembryonic cell adhesion antigen 1a. Immunology 2009;128:e181-e192.

21 Jing X, Chen SS, Jing W, Tan Q, Yu MX, Tu JC: Diagnostic potential of differentially expressed Homer1, IL-1beta, and TNF-alpha in coronary artery disease. Int J Mol Sci 2014;16: 535-546.
22 Singh A, Singh V, Tiwari RL, Chandra T, Kumar A, Dikshit M, Barthwal MK: The IRAKERK-p67phox-Nox-2 axis mediates TLR4, 2 -induced ROS production for IL-1beta transcription and processing in monocytes. Cell Mol Immunol 2016;13:745-763.

23 Walker LR, Hussein HA, Akula SM: Disintegrin-like domain of glycoprotein $\mathrm{B}$ regulates $\mathrm{Ka}$ posi's sarcoma-associated herpesvirus infection of cells. J Gen Virol 2014;95:1770-1782.

24 Rajshankar D, Downey GP, McCulloch CA: IL-1beta enhances cell adhesion to degraded fibronectin. FASEB J 2012;26:4429-4444.

25 Morad SA, Levin JC, Tan SF, Fox TE, Feith DJ, Cabot MC: Novel off-target effect of tamoxifen: inhibition of acid ceramidase activity in cancer cells. Biochim Biophys Acta 2013; 1831:1657-1664.

26 Ensoli B, Sgadari C, Barillari G, Sirianni MC, Sturzl M, Monini P: Biology of Kaposi's sarcoma. Eur J Cancer 2001;37:1251-1269.

27 Host KM, Jacobs SR, West JA, Zhang Z, Costantini LM, Stopford CM, Dittmer DP, Damania B: Kaposi's sarcoma-associated herpesvirus increases $\mathrm{PD}-\mathrm{L} 1$ and proinflammatory cytokine expression in human monocytes. MBio 2017;8:e00917-17.

28 ten Kate M, Hofland LJ, van Grevenstein WM, van Koetsveld PV, Jeekel J, van Eijck $\mathrm{CH}$ : Influence of proinflammatory cytokines on the adhesion of human colon carcinoma cells to lung microvascular endothelium. Int J Cancer 2004;112:943-950.

29 Joos H, Wildner A, Hogrefe C, Reichel H, Brenner RE: Interleukin- 1 beta and tumor necrosis factor alpha inhibit migration activity of chondrogenic progenitor cells from nonfibrillated osteoarthritic cartilage. Arthritis Res Ther 2013;15:R119.

30 Samaniego F, Markham PD, Gallo RC, Ensoli B: Inflammatory cytokines induce AIDSKaposi's sarcoma-derived spindle cells to produce and release basic fibroblast growth factor and enhance Kaposi's sarcoma-like lesion formation in nude mice. J Immunol 1995; 154:3582-3592.

31 Polizzotto MN, Uldrick TS, Wyvill KM, Aleman K, Marshall V, Wang V, Whitby D, Pittaluga S, Jaffe ES, Millo C, Tosato G, Little RF, Steinberg SM, Sereti I, Yarchoan R: Clinical features and outcomes of patients with symp- tomatic Kaposi sarcoma herpesvirus (KSHV)associated inflammation: prospective characterization of KSHV inflammatory cytokine syndrome (KICS). Clin Infect Dis 2016;62: 730-738.

- 32 Goncalves PH, Ziegelbauer J, Uldrick TS, Yarchoan R: Kaposi sarcoma herpesvirus-associated cancers and related diseases. Curr Opin HIV AIDS 2017;12:47-56.

33 Xie J, Pan H, Yoo S, Gao SJ: Kaposi's sarcomaassociated herpesvirus induction of AP- 1 and interleukin 6 during primary infection mediated by multiple mitogen-activated protein kinase pathways. J Virol 2005;79:15027-15037.

- 34 Ankel H, Westra DF, Welling-Wester S, Lebon P: Induction of interferon-alpha by glycoprotein $\mathrm{D}$ of herpes simplex virus: a possible role of chemokine receptors. Virology 1998;251:317-326.

- 35 Mogensen TH, Paludan SR: Molecular pathways in virus-induced cytokine production. Microbiol Mol Biol Rev 2001;65:131-150.

36 Carlquist JF, Edelman L, Bennion DW, Anderson JL: Cytomegalovirus induction of interleukin-6 in lung fibroblasts occurs independently of active infection and involves a $G$ protein and the transcription factor, NF-kappaB. J Infect Dis 1999;179:1094-1100.

37 Dyson OF, Traylen CM, Akula SM: Cell membrane-bound Kaposi's sarcoma-associated herpesvirus-encoded glycoprotein B promotes virus latency by regulating expression of cellular Egr-1. J Biol Chem 2010;285: 37491-37502.

38 Pohlman TH, Stanness KA, Beatty PG, Ochs HD, Harlan JM: An endothelial cell surface factor(s) induced in vitro by lipopolysaccharide, interleukin 1 , and tumor necrosis factoralpha increases neutrophil adherence by a CDw18-dependent mechanism. J Immunol 1986;136:4548-4553.

39 Mesri EA, Cesarman E, Arvanitakis L, Rafii S, Moore MA, Posnett DN, Knowles DM, Asch AS: Human herpesvirus-8/Kaposi's sarcomaassociated herpesvirus is a new transmissible virus that infects B cells. J Exp Med 1996;183: 2385-2390.

40 Bryan BA, Dyson OF, Akula SM: Identifying cellular genes crucial for the reactivation of Kaposi's sarcoma-associated herpesvirus latency. J Gen Virol 2006;87:519-529. 